\title{
HUBUNGAN KARAKTERISTIK PETANI DAN TINGKAT ADOPSI TEKNOLOGI PADA USAHATANI BAWANG MERAH DI DESA TONSEWER, KECAMATAN TOMPASO
}

\author{
Alfons Manongko \\ Caroline B.D. Pakasi \\ Lyndon Pangemanan
}

\begin{abstract}
This study aims to analyze the relationship between the characteristics of farmers with the level of adoption and application of technological innovation in onion farming in Tonsewer Village, Tompaso Subdistrict, Minahasa Regency, North Sulawesi Province. This research was conducted from February to March 2017. This research used primary and secondary data. Primary data were collected by interviewing onion farmers using questionnaires. Sampling of 48 people. Analysis method using Descriptive Analysis. The study found that the technological adoption rate in Tonsewer village is very high and has adopted the technology. Factors influencing the adoption rate are land area, farming, income, formal education, non-formal education, age, and cosmopolitan level. Spearman's correlation value of land area, income, formal education, non-formal education and cosmopolitan level shows the direction of positive correlation, while age shows the direction of negative correlation to the adoption rate of onion technology.
\end{abstract}

Keywords: farmer characteristics, technology adoption rate, Tonsewer Village, Tompaso Sub-district, Minahasa District

\begin{abstract}
ABSTRAK
Untuk menganalisis hubungan karakteristik petani dan tingkat adopsi teknologi pada usahatani bawang merah di Desa Tonsewer, Kecamatan Tompaso, Kabupaten Minahasa. Penelitian ini bertujuan untuk menganalisis hubungan karakteristik petani dengan tingkat adopsi dan penerapan inovasi teknologi pada usahatani bawang merah di Desa Tonsewer, Kecamatan Tompaso, Kabupaten Minahasa, Provinsi Sulawesi Utara. Penelitian ini dilaksanakan dari bulan Februari sampai Maret 2017. Penelitian ini menggunakan data primer dan sekunder. Data primer dikumpulkan dengan cara mewawancarai petani bawang merah dengan menggunakan kuesioner. Pengambilan sampel sebanyak 48 orang. Metode analisis menggunakan Analisis Deskriptif. Penelitian ini menemukan bahwa tingkat adopsi teknologi di desa Tonsewer sudah sangat tinngi dan sudah menerapkan adopsi. Faktor yang mempengaruhi tingkat adopsi yaitu luas lahan, usahatani, pendapatan, pendidikan formal, pendidikan non-formal, umur, dan tingkat kosmopolitan. Nilai korelasi Spearman luas lahan, pendapatan, pendidikan formal, pendidikan non formal dan tingkat kosmopolitan menunjukkan arah korelasi positif, sedangkan umur menunjukkan arah korelasi negatif terhadap tingkat adopsi teknologi bawang merah.
\end{abstract}

Kata kunci : karakteristik petani, tingkat adopsi teknologi, Desa Tonsewer, Kecamatan Tompaso, Kabupaten Minahasa 


\section{PENDAHULUAN}

\section{Latar Belakang}

Sektor pertanian banyak memberikan sumbangan bagi perekonomian Indonesia. Revolusi di bidang pertanian atau revolusi hijau sangat berjasa bagi kehidupan umat manusia di bumi ini, terutama dalam pemenuhan kebutuhan pangan. Revolusi hijau ditandai dengan adanya pemuliaan tanaman, pemupukan serta pemberantasan hama dan penyakit secara intensif. Namun di balik revolusi hijau tersebut ternyata terdapat bencana yang dapat merugikan lingkungan hidup dan kesehatan manusia. Menurut Soetrisno (2002), secara makro program revolusi hijau berhasil karena mampu meningkatkan produktivitas sub-sektor pertanian pangan, akan tetapi secara mikro revolusi hijau menimbulkan permasalahan sendiri. Salah satu masalah yang penting adalah terjadi uniformitas bibit tanaman di Indonesia. Hal tersebut mengakibatkan sub-sektor pertanian pangan rentan terhadap barbagai hama. Meskipun produktivitas sub-sektor pertanian pangan tinggi, tetapi tidak memiliki ketahanan hidup yang lama. Revolusi hijau juga membuat petani menjadi bodoh.

Banyak pengetahuan lokal dilupakan oleh petani. Ketergantungan pada teknologi industri pertanian membuat rentan terjadinya objek permainan produk-produk seperti pupuk kimia. Selain itu, juga digunakan pestisida sebagai salah satu cara untuk mengendalikan hama yang bisa merugikan panen mereka. Sering kali cara yang dilakukan tersebut justru membahayakan, dimana pupuk kimia yang digunakan membuat kondisi tanah kurang subur, pestisida mengakibatkan pencemaran lingkungan dan hilangnya predator alami yang justru berperan dalam menciptakan keseimbangan ekosistem. Melihat kenyataan ini, perlu adanya sistem yang menjamin terciptanya lingkungan yang sehat dan ramah yang salah satunya melalui sistem organik. Bawang merah (Allium ascalonicum) merupakan salah satu jenis sayuran yang memiliki banyak manfaat dan bernilai ekonomis tinggi. Permintaan bawang merah segar untuk konsumsi rumah tangga dan bahan baku industri pengolahan di dalam negeri terus mengalami peningkatan setiap tahun sejalan dengan perkembangan jumlah penduduk dan pertumbuhan industri makanan. Oleh karena itu produksi bawang merah yang berkualitas harus ditingkatkan dan diproduksi sepanjang tahun agar pasokan tersedia dan harganya tidak berfluktuasi. Usahatani bawang merah memiliki risiko tinggi, banyak tantangan dan kendala yang dihadapi dalam budidayanya, seperti serangan organisme pengganggu tanaman (OPT) yang dapat menggagalkan panen. Produktivitas tanaman yang rendah dengan serangan hama dan penyakit yang semakin meningkat umumnya terjadi pada pertanaman bawang merah di luar musim atau off-season.

Penanaman bawang merah di musim hujan yaitu mulai bulan Oktober/Desember sampai bulan Maret/April dalam kondisi iklim normal biasa disebut tanaman off-season. Fenomena bawang merah off-season tersebut umumnya terkait dengan langkanya hasil produksi bawang merah di saat musim hujan yang dihasilkan dari daerah sentra produksi utama di Pulau Jawa seperti Cirebon, Brebes, Tegal, dan Nganjuk. Luas areal tanam bawang merah off-season di daerah sentra produksi utama tersebut sedikit yaitu $<30 \%$ dari pertanaman di musim kemarau (in-season) dengan ciri mutu hasil bawang kurang baik, ukuran umbinya kecil-kecil, warnanya pucat dan aromanya kurang menyengat. Bawang merah telah menjadi perhatian pemerintah dalam mengembangkan sentra bawang baru di lahan kering, di mana upaya pengembangan komoditas ini diharapkan mampu mengatasi penyediaan produksi bawang merahdalam negeri sepanjang tahun. Selain itu, bawang akan dapat mengatasi kekurangan pasokan bawang merah yang sering kali menimbulkan fluktuasi harga bawang merah yang sangat tajam dan membebani masyarakat. Budidaya bawang merah di lahan kering merupakan suatu terobosan teknologi untuk meningkatkan kesejahteraan petani, karena usahatani bawang merah di lahan sawah pada musim hujan dianggap tidak efisien dan tidak menguntungkan.mempengaruhi pengambilan keputusan petani terhadap suatu inovasi, yaitu budidaya bawang merah.

Menurut IFOAM (International Federation of Organic Agriculture Movement, 1997), tujuan yang hendak dicapai melalui penggunaan sistem pertanian organik adalah :

1. Menghasilkan bahan pangan dengan kualitas nutrisi tinggi serta dalam jumlah yang cukup. 
2. Melaksanakan interaksi efektif dengan sistem dan daur alamiah yang mendukung semua bentuk kehidupan yang ada.

3. Mendorong dan meningkatkan daur ulang dalam sistem usahatani dengan mengaktifkan kehidupan jasad remik, flora dan fauna, tanah, tanaman serta hewan.

4. Memelihara serta meningkatkan kesuburan tanah secara berkelanjutan.

5. Menggunakan sebanyak mungkin sumbersumber terbaharui yang berasal dari sistem usaha tani itu sendiri.

6. Memanfaatkan bahan-bahan yang mudah didaur ulang baik didalam maupun di luar usahatani.

7. Menciptakan keadaan yang memungkinkan ternak hidup sesuai dengan perilakunya yang hakiki.

8. Membatasi terjadinya semua bentuk pencemaran lingkungan yang mungkin dihasilkan oleh kegiatan pertanian.

9. Mempertahankan keanekaragaman hayati termasuk pelestarian habitat tanaman dan hewan.

10. Memberikan jaminan yang semakin baik bagi para produsen pertanian (terutama petani) dengan kehidupan yang lebih sesuai dengan hak asasi dan manusia untuk memenuhi kebutuhan dasar serta memperoleh penghasilan dan kepuasan kerja, termasuk lingkungan kerja yang aman dan sehat.

11. Mempertimbangkan dampak yang lebih luas dari kegiatan usahatani terhadap kondisi fisik dan sosial.

Adopsi inovasi dapat diartikan sebagai penerapan atau penggunaan suatu ide, alat-alat, atau teknologi "baru" yang disampaikan berupa pesan komunikasi (lewat penyuluhan).Manifestasi dari bentuk adopsi inovasi ini dapat dilihat atau diamati berupa tingkah laku, metode, maupun peralatan dan teknologi yang dipergunakan dalam kegiatan usahataninya (Levis, 1996).

\section{Rumusan Masalah}

Tingkat adopsi teknologi pada petani bawang merah sebagai dasar untuk menerapkan strategi yang diperlukan dalam rangka mendukung tujuan jangka panjang bisa terwujud melalui metode metode inovasi tersebut. Berkaitan dengan hal tersebut maka timbul pertanyaan sebagai berikut: Bagaimana hubungan antara karakteristik petani dan tingkat adopsi teknologi pada usahatani bawang merah bawang merah di Desa Tonsewer?

\section{Tujuan}

Untuk menganalisis hubungan karakteristik petani dan tingkat adopsi teknologi pada usahatani bawang merah di Desa Tonsewer Kecamatan Tompaso.

\section{Manfaat}

Diharapkan dapat memberikan gambaran umum tentang adopsi inovasi. Disamping itu, dengan diketahuinya inovasi baru pemerintah terlebih khusus para penyuluh dapat menindak lanjuti adopsi inovasi teknologi usahatani, kepada petani lain yang belum melakukan menerapkan inovasi baru tersebut.

\section{METODOLOGI PENELITIAN}

\section{Tempat dan Waktu Penelitian}

Pengambilan lokasi dilakukan secara sengaja karena berdasarkan ciri-ciri atau sifatsifat yang diketahui sebelumnya sesuai dengan kepentingan penelitian. Desa Tonsewer dipilih karena merupakan salah satu daerah sentra produksi Bawang merah (Allium ascalonicum) di Kabupaten Minahasa. Penelitian dilaksanakan mulai bulan Februari 2017 Maret 2017 di Desa Tonsewer Kecamatan Tompaso.

\section{Metode Pengumpulan Data}

Pengambilan data dilakukan dengan teknik survey. Dalam teknik survey informasi yang dikumpulkan dari responden dengan menggunakan kuisioner. Data primer diperoleh dari wawancara berdasarkan daftar pertanyaan yang sudah disusun sebelumnya kepada petani bawang merah yang ada di Desa Tonsewer. Data sekunder diperoleh dari Pemerintah Desa Tonsewer dan buku-buku yang terkait dengan penelitian ini dan data-data juga diperoleh melalui dokumentasi dari peneliti dan kantor Desa Tonsewer. 


\section{Metode Pengambilan Sampel}

Pengambilan data dilakukan dengan membagikan kuesioner kepada petani, dan penentuan sampel dilakukan dengan metode pengambilan sampel acak sederhana. Jumlah populasi petani bawang merah di Desa Tonsewer sebanyak 215 orang dan diambil adalah sebanyak 48 orang atau sama dengan $22,01 \%$ sebagai sampel dari populasi desa tersebut. Jumlah sampel keseluruhan yang diambil adalah sebanyak 48 orang. Jumlah tersebut sudah dapat mempresentasikan keadaan petani di Desa Tonsewer, 48 orang pada umumnya dan merupakan ukuran yang dapat diterima serta memenuhi syarat dari suatu metode penelitian jenis deskriptif korelasional (Gay dalam Hasan, 2002).

\section{Hipotesis Penelitian}

- Diduga ada hubungan nyata antara luas lahan usaha tani dengan tingkat adopsi inovasi budidaya bawang merah pada petani.

- Diduga ada hubungan nyata antara pendapatan dengan tingkat adopsi inovasi budidaya bawang merah pada petani.

- Diduga ada hubungan nyata antara pendidikan formal dengan tingkat adopsi inovasi budidaya bawang merah pada petani.

- Diduga ada hubungan nyata antara pendidikan non formal dengan tingkat adopsi inovasi budidaya bawang merah pada petani.

- Diduga ada hubungan nyata antara umur petani dengan tingkat adopsi inovasi budidaya Bawang merah (Allium ascalonicum) pada petani.

- Diduga ada hubungan nyata antara tingkat kekosmopolitan petani dengan tingkat adopsi inovasi budidaya Bawang merah (Allium ascalonicum) pada petani.

$\underline{\text { Kriteria uji : }}$

- Jika Sig. $\leq \alpha(0,1)$ berarti ada hubungan nyata antara kedua variabel.

- Jika Sig. $>\alpha(0,1)$ berarti tidak ada hubungan yang nyata antara kedua variabel.

\section{Pengukuran Variabel}

Tabel 1.Pengukuran Variabel Sosial Ekonomi

\begin{tabular}{|c|c|c|c|}
\hline Variabel & Indikator & Kriteria & Skor \\
\hline Luas lahan & - Luas lahan & $>3 \mathrm{Ha}$ & 5 \\
\hline \multirow[t]{4}{*}{ Usahatani } & yang & $2,1-3 \mathrm{Ha}$ & 4 \\
\hline & diusahakan & $1,1-2 \mathrm{Ha}$ & 3 \\
\hline & & $0,5-1 \mathrm{Ha}$ & 2 \\
\hline & & $<0,5 \mathrm{Ha}$ & 1 \\
\hline \multirow[t]{14}{*}{ Pendapatan } & - Pendapatan & $>\mathrm{Rp}$ & 5 \\
\hline & bersih & 15.000 .000 & \\
\hline & Petani & Rp 10.000.050 & 4 \\
\hline & dalam1 kali & - & \\
\hline & musim & Rp 15.000.000 & \\
\hline & tanam & Rp. 7.500 .000 & 3 \\
\hline & & - & \\
\hline & & $\mathrm{Rp}$ & \\
\hline & & 10.000 .000 & \\
\hline & & Rp. 5.000 .000 & \\
\hline & & - & 2 \\
\hline & & Rp 7.000 .000 & \\
\hline & & $<\mathrm{Rp}$ & 1 \\
\hline & & 5.000 .000 & \\
\hline \multirow{5}{*}{$\begin{array}{l}\text { Pendidikan } \\
\text { Formal }\end{array}$} & - Pendidikan & > SMU/SMK & 5 \\
\hline & formal yang & SMU/SMK & 4 \\
\hline & telah & SMP & 3 \\
\hline & ditemnuh & SD & 2 \\
\hline & $\begin{array}{l}\text { petani } \\
\text { pempun }\end{array}$ & $\begin{array}{c}\text { Tidak Tamat } \\
\text { SD }\end{array}$ & 1 \\
\hline Pendidikan & - Frekuensi & $>12$ & 5 \\
\hline \multirow[t]{5}{*}{ Non-Formal } & Petani & $10-12$ kali & 4 \\
\hline & mengikuti & $5-9$ kali & 3 \\
\hline & kegiatan & $1-4$ kali & 2 \\
\hline & penyuluhan & Tidak Pernah & 1 \\
\hline & Tahun & & \\
\hline \multirow[t]{5}{*}{ Umur } & - Frekuensi & 25 - 39 Tahun & 5 \\
\hline & responden & $40-50$ Tahun & 4 \\
\hline & pegi ke Kota & $51-60$ Tahun & 3 \\
\hline & dalam 1 & 61 - 70 Tahun & 2 \\
\hline & bulan & > 70Tahun & 1 \\
\hline \multirow{5}{*}{$\begin{array}{l}\text { Tingkat } \\
\text { Kosmopolit } \\
\text { an }\end{array}$} & - Frekuensi & $\geq 6$ kali & 5 \\
\hline & responden & 5 kali & 4 \\
\hline & pegi ke Kota & 4 kali & 3 \\
\hline & dalam 1 & 3 kali & 2 \\
\hline & bulan & $1-2$ kali & 1 \\
\hline
\end{tabular}


Tabel 2. Pengukuran Variabel Tahap Pengolahan Tanah

\begin{tabular}{|c|c|c|c|}
\hline Variabel & Indikator & Kriteria & Skor \\
\hline \multirow[t]{5}{*}{$\begin{array}{l}\text { Pengolahan } \\
\text { tanah }\end{array}$} & $\begin{array}{l}\text { - Melakukan } \\
\text { pembersihan lahan }\end{array}$ & $\begin{array}{l}\text { - Melakukan } 5 \\
-6 \text { tahapan } \\
\text { pengolahan } \\
\text { tanah }\end{array}$ & 5 \\
\hline & $\begin{array}{l}\text { - Melakukan } \\
\text { pembajakan tanah } \\
\text { yang sebelumnya } \\
\text { telah digenangi air } \\
\text { dengan } \\
\text { menggunakan } \\
\text { traktor/ bajak } \\
\text { (pembajakan) }\end{array}$ & $\begin{array}{l}\text { - Melakukan } 3 \\
\text { - } 4 \text { tahapan } \\
\text { pengolahan } \\
\text { tanah }\end{array}$ & 4 \\
\hline & $\begin{array}{l}\text { - Melakukan } \\
\text { Penggaruan untuk } \\
\text { menghancurkan } \\
\text { bongkahan- } \\
\text { bongkahan tanah } \\
\text { menjadi lebih kecil } \\
\text { (penggaruan) }\end{array}$ & $\begin{array}{l}\text { - Melakukan } 2 \\
\text { tahapan } \\
\text { pengolahan } \\
\text { tanah }\end{array}$ & 3 \\
\hline & $\begin{array}{l}\text { - Penghancuran } \\
\text { lapisan tanah }\end{array}$ & $\begin{array}{l}\text { - Melakukan } 1 \\
\text { tahapan } \\
\text { pengolahan } \\
\text { tanah }\end{array}$ & 2 \\
\hline & $\begin{array}{l}\text { - Persiapan lahan } \\
\text { penanaman }\end{array}$ & $\begin{array}{l}\text { - Tidak } \\
\text { melakukan } \\
\text { tahapan }\end{array}$ & 1 \\
\hline
\end{tabular}

Tabel 3. Pengukuran Tahap Penanaman

\begin{tabular}{|c|c|c|c|}
\hline Variabel & Indikator & Kriteria & Skor \\
\hline \multirow[t]{5}{*}{ Penanaman } & $\begin{array}{l}\text { - Penjemuran } \\
\text { benih selama } 1 \\
2 \text { jam }\end{array}$ & 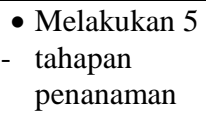 & 5 \\
\hline & $\begin{array}{l}\text { - Seleksi benih } \\
\text { dilakukan } \\
\text { dengan } \\
\text { merendam, } \\
\text { benih yang } \\
\text { baik adalah } \\
\text { yang } \\
\text { tenggelam, } \\
\text { pengaplikasia } \\
\text { n fungisida, } \\
\text { dicampur } \\
\text { bersama air } \\
\text { rendaman }\end{array}$ & $\begin{array}{l}\text { - Melakukan } 4 \\
\text { tahapan } \\
\text { penanaman }\end{array}$ & 4 \\
\hline & $\begin{array}{l}\text { - Benih terpilih } \\
\text { kemudian } \\
\text { ditiriskan }\end{array}$ & $\begin{array}{l}\text { - Melakukan } 3 \\
\text { tahapan } \\
\text { penanaman }\end{array}$ & 3 \\
\hline & $\begin{array}{l}\text { - } \text { Pemeraman } \\
\text { selama } \pm 48 \\
\text { jam }\end{array}$ & $\begin{array}{l}\text { - Melakukan } 2 \\
\text { tahapan } \\
\text { penanaman }\end{array}$ & 2 \\
\hline & $\begin{array}{l}\text { - Benih ditabur } \\
\text { pada areal } \\
\text { penanaman } \\
\text { dengan } \\
\text { kerapatan } \pm \\
50 \mathrm{gr} / 1 \mathrm{~m}^{2}\end{array}$ & $\begin{array}{l}\text { - Melakukan } \\
\text { hanya } 1 \\
\text { tahapan } \\
\text { penanaman }\end{array}$ & 1 \\
\hline
\end{tabular}

Tabel 4. Pengukuran Variabel Pemupukan

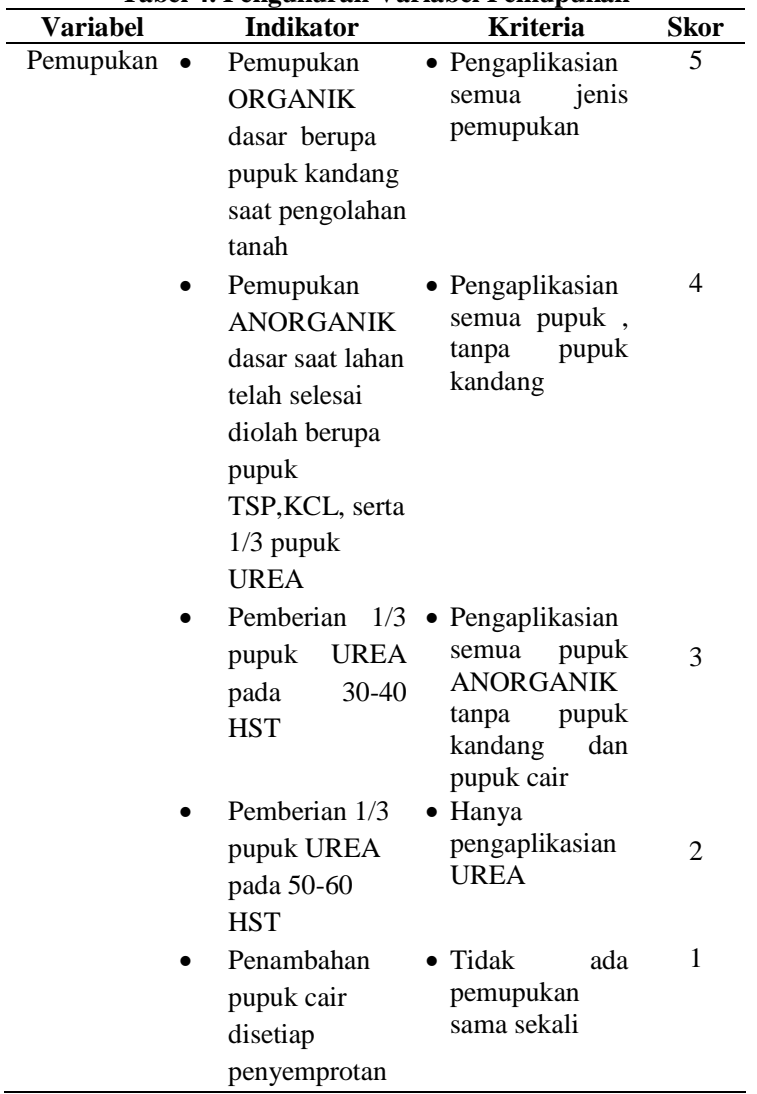

Tabel 5. Pengukuran Variabel Pengairan

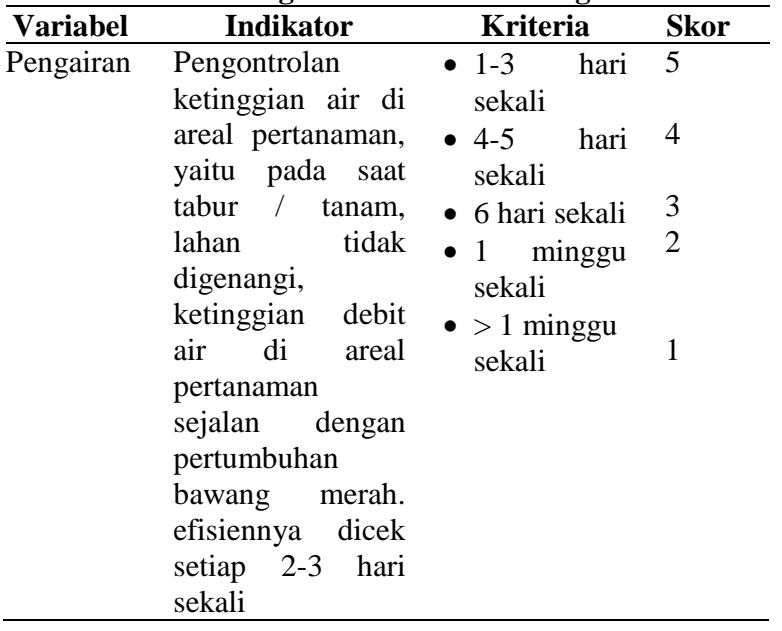

Mengidentifikasi adanya gejala seranganserangan hama dan penyakit pada areal pertanaman dianjurkan dilakukan secara berkala dan kontinyu, agar pengendalian dapat dilakukan secara efektif dan tepat guna. Pengendalian dilakukan apabila terdapat gejala serangan, dapat dilakukan secara fisik, biologis, kimia, maupun kultur teknis. 
Tabel 6. Pengukuran Variabel Pada Tahap Pengendalian Hama, Penyakit Serta Gulma

\begin{tabular}{|c|c|c|c|}
\hline Variabel & Indikator & Kriteria & Skor \\
\hline \multirow[t]{5}{*}{$\begin{array}{l}\text { Pengendalian } \\
\text { Hama, } \\
\text { Penyakit, } \\
\text { serta Gulma }\end{array}$} & $\begin{array}{l}\text { - Pencelupan } \\
\text { benih pada } \\
\text { larutan fungisida } \\
\text { saat perendaman }\end{array}$ & $\begin{array}{l}\text { - Melakukan } 4 \text { - } \\
5 \text { kegiatan } \\
\text { PHP tanaman }\end{array}$ & 5 \\
\hline & $\begin{array}{l}\text { - Sanitasi areal } \\
\text { pertanaman } \\
\text { - Melakukan } \\
\text { pemberantasan } \\
\text { gulma saat } \\
\text { terdeteksi, baik }\end{array}$ & $\begin{array}{l}\text { - Melakukan } \\
\text { pengendalian } \\
\text { PHP tanpa } \\
\text { sanitasi areal } \\
\text { pertanaman }\end{array}$ & 4 \\
\hline & $\begin{array}{l}\text { fisik maupun } \\
\text { kimia } \\
\text { - Melakukan } \\
\text { pengendalian } \\
\text { dgn pestisida } \\
\text { sesuai dengan } \\
\text { gejala yang }\end{array}$ & $\begin{array}{l}\text { - Melakukan } \\
\text { hanya } 3 \\
\text { pengendalian, } \\
\text { hama, } \\
\text { penyakit, dan } \\
\text { gulma }\end{array}$ & 3 \\
\hline & $\begin{array}{l}\text { terlihat baik } \\
\text { fisik, kultur } \\
\text { teknis, maupun } \\
\text { kimia } \\
\text { - Melakukan } \\
\text { pengendalian }\end{array}$ & $\begin{array}{l}\text { - Hanya } \\
\text { melakukan } 2 \\
\text { pengendalian, } \\
\text { hama dan } \\
\text { penyakit }\end{array}$ & 2 \\
\hline & $\begin{array}{l}\text { saat mulai } \\
\text { terlihat adanya } \\
\text { gejala penyakit, } \\
\text { dengan } \\
\text { penyemprotan } \\
\text { fungisida, } \\
\text { maupun } \\
\text { pencabutan } \\
\text { tanaman yang } \\
\text { terinfeksi }\end{array}$ & $\begin{array}{l}\text { - Hanya } \\
\text { melakukan } 1 \\
\text { pengendalian }\end{array}$ & 1 \\
\hline
\end{tabular}

Tabel 7. Pengukuran Variabel Pada Tahap Panen Dan Pasca Panen

\begin{tabular}{|c|c|c|c|}
\hline Variabel & Indikator & Kriteria & Skor \\
\hline \multirow[t]{3}{*}{$\begin{array}{l}\text { Panen } \\
\text { dan pasca } \\
\text { panen }\end{array}$} & $\begin{array}{l}\text { - Umur panen } \\
\text { bawang } \\
\text { merah yang } \\
\text { baik } 65-75\end{array}$ & $\begin{array}{l}\text { - Melakukan semua } \\
\text { kegiatan panen dan } \\
\text { pasca panen }\end{array}$ & 5 \\
\hline & $\begin{array}{l}\text { hari setelah } \\
\text { tanam, atau } \\
\text { tergantung } \\
\text { varietas } \\
\text { - Pemanenan } \\
\text { menggunakan }\end{array}$ & $\begin{array}{l}\text { - Melakukan semua } \\
\text { kegiatan panen dan } \\
\text { pasca panen, tanpa } \\
\text { melakukan } \\
\text { penggilingan }\end{array}$ & 4 \\
\hline & $\begin{array}{l}\text { alat panen } \\
\text { berupa } \\
\text { cangkul atau } \\
\text { parang. } \\
\text { - Pengangkutan } \\
\text { ke tempat } \\
\text { penampung. }\end{array}$ & $\begin{array}{l}\text { - Melakukan semua } \\
\text { kegiatan panen dan } \\
\text { pasca panen, tanpa } \\
\text { melakukan } \\
\text { penjemun }\end{array}$ & 3 \\
\hline
\end{tabular}

\section{Metode Analisis}

Metode analisis menggunakan Analisis Deskriptif, dimana untuk mengkaji Karakteristik Sosial Ekonomi Petani dan Tingkat Adopsi Inovasi Teknologi Budidaya Bawang merah (Allium ascalonicum) menggunakan rumus Median. Pengukuran Variabel Deskriptif.

\begin{tabular}{|l|l|}
\hline Karakteristik & Point/Skor \\
\hline Sangat Buruk & 1 \\
\hline Buruk & 2 \\
\hline Sedang & 3 \\
\hline Baik & 4 \\
\hline Tinggi & 5 \\
\hline
\end{tabular}

Ket: Tolak ukur Jumlah Median adalah 1-3 tergolong sedang dan 4-5 tergolong Tinggi.

Sedangkan untuk mengetahui hubungan faktor-faktor sosial ekonomi petani dengan tingkat adopsi inovasi teknologi budidaya Bawang Merah adalah dengan menggunakan uji korelasi Rank Spearman ( $\gamma s)$. Sedangkan untuk mengetahui nilai koefisien korelasi $(\gamma s)$ menggunakan Program SPSS 17.

Rumus :

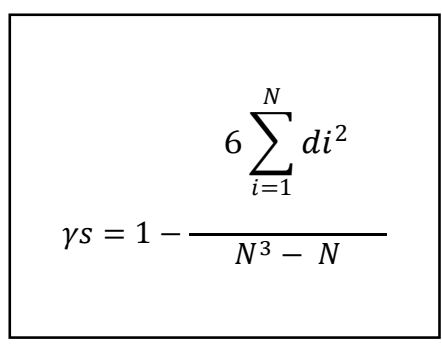

\section{Keterangan}

$\gamma s=$ Koefisien Korelasi Rank Spearman

$N=$ Jumlah Sampel

$d i=$ Selisih antara Ranking Variabel

Interpretasi hasil uji koefisien korelasi Rank Spearman $(\gamma s)$ digunakan tabel sebagai berikut (Dahlan, 2011) :

\begin{tabular}{ll}
\hline NILAI & INTERPRETASI \\
\hline $0,00-0,199$ & Sangat Lemah \\
$0,20-0,399$ & Lemah \\
$0,40-0,599$ & Sedang \\
$0,60-0,799$ & Kuat \\
$0,80-1,000$ & Sangat Kuat \\
\hline
\end{tabular}

\section{HASIL DAN PEMBAHASAN}

\section{Gambaran Umum Lokasi Penelitian}

Penduduk Desa Tonsewer merupakan penduduk asli Minahasa, Topografi Desa Tonsewer ada yang dataranya rendah $50 \mathrm{Ha}$, tinggi $12 \mathrm{Ha}$, dan berbukit-bukit $50 \mathrm{Ha}$ dengan curah hujan setiap tahunnya rata-rata 180,79 $\mathrm{mm} / \mathrm{tahun}$, dan tekstur tanah sangat cocok untuk dijadikan sebagai areal pertanaman dan 
luas wilayah Desa Tonsewer kecamatan Tompaso II kira-kira 254Ha.

Desa Tonsewer secara administrasi terletak di Kecamatan Tompaso II Kabupaten Minahasa dengan luas mencapai $254 \mathrm{Ha}$ dan berjarak 50 KM, dari Kota Manado Ibukota Provinsi Sulawesi Utara atau dapat diakses dengan waktu tempuh kira kira 1 jam perjalanan, serta dapat diakses selama 30 Menit perjalanan dari Kota Tomohon yang berjarak kurang lebih $20 \mathrm{KM}$. Adapun batas- batas Desa Tonsewer adalah sebagai berikut :

- Sebelah Utara berbatasan dengan Desa Sendangan dan Desa Pinabetengan

- Sebelah Selatan berbatasan dengan Desa Tonsewer Selatan

- Sebelah Timur berbatasan dengan desa Touure II, Kamanga

- Sebelah Barat berbatasan dengan Desa Pinabetengan dan Pinabetengan Selatan

\section{Keadaan Penduduk}

Jumlah penduduk Desa Tonsewer pada tahun 2015 adalah 933 jiwa, yang terdiri dari 484 Laki-Laki atau 51,87 \% dan perempuan 449 Perempuan atau 48,12\%. Jumlah penduduk Desa Tonsewer tidak terdapat perbedaan yang signifikan antara jumlah penduduk laki-laki dan perempuan. Mata pencaharian sebagian besar penduduk Desa Tonsewer ialah sektor pertanian, yaitu sebesar $80 \%$, hal ini dikarenakan kondisi wilayah yang masih banyak terdapat lahan pertanian dan pekerjaan ini sudah dilakukan turun-temurun, banyak penduduk yang memiliki lebih dari satu pekerjaan atau pekerjaan sampingan. Jenis pekerjaan penduduk Desa Tonsewer secara rinci dilihat pada Tabel 8 .

Tabel 8. Jenis Pekerjaan Penduduk Desa Tonsewer

\begin{tabular}{cccc}
\multicolumn{4}{c}{ Tahun 2015 } \\
\hline No & Jenis Pekerjaan & $\begin{array}{c}\text { Jumlah } \\
\text { (orang) }\end{array}$ & $\%$ \\
\hline 1 & Petani & 240 & 76,92 \\
2 & Peternak & 6 & 1,92 \\
3 & Montir & 2 & 0,64 \\
4 & PNS & 16 & 5,12 \\
5 & TNI / POLRI & 2 & 0,64 \\
6 & Buruh Bangunan & 7 & 2,24 \\
7 & Pedagang & 33 & 10,57 \\
8 & Pengrajin & 1 & 0,32 \\
9 & Pensiunan & 6 & 1,92 \\
\hline Jumlah & (PNS,TNI,POLRI) & \multicolumn{3}{c}{312} \\
\hline Sumber : Sekertaris Desa Tonsewer
\end{tabular}

Namun, pada saat penelitian dilakukan, data desa tersebut masih belum tersedia dikarenakan semua data administratif desa masih belum rampung.

\section{Karakteristik Responden}

Dalam penelitian ini terdapat 48 responden, yang secara keseluruhan berjenis kelamin laki-laki. Responden merupakan petani Bawang merah yang ada di Desa Tonsewer.

\section{Karakteristik Sosial Ekonomi Responden}

Karakteristik yang digunakan dalam penelitian ini adalah Luas Lahan, Pendapatan, Pendidikan Formal, Pendidikan Non Formal, Umur, dan Tingkat Kekosmopolitan.

\section{1) Luas Lahan}

Luas lahan responden dihitung berdasarkan luas lahan usahatani yang dimiliki atau diusahakan oleh responden yang dinyatakan dalam hektar disajikan dalam Tabel 9.

\begin{tabular}{|c|c|c|c|c|c|}
\hline Variabel & Kriteria & Skor & $\begin{array}{c}\text { Jumlah } \\
\text { responden }\end{array}$ & $\%$ & Median \\
\hline \multirow{5}{*}{$\begin{array}{l}\text { Luas } \\
\text { Lahan }\end{array}$} & - $>3 \mathrm{Ha}$ & 5 & 8 & 16,67 & \multirow{5}{*}{3} \\
\hline & - $2,1-3 \mathrm{Ha}$ & 4 & 4 & 8,33 & \\
\hline & - $1,1-2 \mathrm{Ha}$ & 3 & 19 & 39,58 & \\
\hline & - $0,5-1 \mathrm{Ha}$ & 2 & 16 & 33,33 & \\
\hline & - $<0,5 \mathrm{Ha}$ & 1 & 1 & 2,08 & \\
\hline Jumlah & & & 48 & 100,00 & \\
\hline
\end{tabular}

Tabel 9 menunjukkan luas lahan yang diusahakan responden.Berdasarkan keterangan tersebut dapat disimpulkan bahwa luas lahan yang dimiliki oleh responden sebagian besar tergolong sedang dengan median 3 .

2) Pendapatan

Pendapatan seseorang akan mempengaruhi tindaklanjut adopsi suatu inovasi, Petani dengan modal besar cenderung lebih berani dalam mencoba inovasi tersebut, Distribusi pendapatan responden disajikan dalam Tabel 10. 


\begin{tabular}{|c|c|c|c|c|c|}
\hline Variabel & Kriteria & Skor & $\begin{array}{c}\text { Jumlah } \\
\text { responden }\end{array}$ & $\%$ & Median \\
\hline \multirow[t]{5}{*}{ Pendapatan } & - >Rp15,000,000 & 5 & 15 & 31,25 & \multirow{6}{*}{4} \\
\hline & $\begin{array}{l}\text { - Rp11,000,000- } \\
\text { Rp15,000,000 }\end{array}$ & 4 & 14 & 29,17 & \\
\hline & $\begin{array}{r}-\operatorname{Rp} 7,500,000- \\
\quad \operatorname{Rp} 10,000,000\end{array}$ & 3 & 7 & 14,58 & \\
\hline & $\begin{array}{l}\text { - Rp5 } 5,000,000- \\
\text { Rp 7,000,000 }\end{array}$ & 2 & 4 & 8,33 & \\
\hline & - $<\mathrm{Rp} 5,000,000$ & 1 & 8 & 16,67 & \\
\hline Jumlah & & & 48 & 100,00 & \\
\hline
\end{tabular}

Tabel 10 menunjukkan bahwa tingkat pendapatan petani tergolong tinggi dengan median 4. Hal ini mengisyaratkan dengan pendapatan responden yang lebih tinggi, responden lebih berani dalam mengambil keputusan untuk menerapkan inovasi baru, khususnya budidaya bawang merah, Pekerjaan responden selain sebagai petani bawang merah juga berprofesi sebagai petani ladang, buruh tani, PNS, buruh bangunan, pedagang, pengerajin, dan pensiunan dan sebagainya

3) Pendidikan Formal

Pendidikan formal yang ditempuh oleh responden dapat mempengaruhi pola pikir dalam menanggapi inovasi-inovasi baru yang diterimanya. Distribusi pendidikan formal responden disajikan dalam Tabel 11.

\begin{tabular}{|c|c|c|c|c|c|}
\hline Variabel & Kriteria & Skor & $\begin{array}{l}\text { Jumlah } \\
\text { Responden }\end{array}$ & $\%$ & Median \\
\hline \multirow{5}{*}{$\begin{array}{c}\text { Pendidikan } \\
\text { Formal }\end{array}$} & >SMU/SMK & 5 & 11 & 22,92 & \multirow{6}{*}{4} \\
\hline & SMU/SMK & 4 & 14 & 29,17 & \\
\hline & SMP & 3 & 11 & 22,92 & \\
\hline & SD & 2 & 9 & 18,75 & \\
\hline & $\begin{array}{l}\text { Tidak Tamat } \\
\text { SD }\end{array}$ & 1 & 3 & 6,25 & \\
\hline Jumlah & & & 48 & 100,00 & \\
\hline
\end{tabular}

Tabel 11 menunjukkan bahwa responden yang pendidikan formal dengan median 4, dapat disimpulkan tingkat kesadaran masyarakat akan pendidikan formal sudah tinggi.

4) Pendidikan Non-Formal

Pendidikan non formal dinyatakan dari berapa kali responden mengikuti kegiatan penyuluhan pertanian dalam 1 tahun terakhir, distribusi pendidikan non formal responden disajikan dalam Tabel 12.

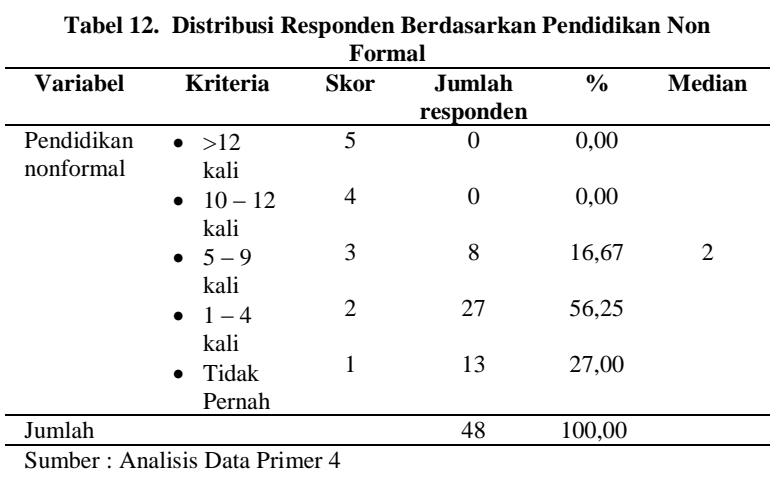

Tabel 12 menunjukkan pendidikan nonformal responden sebagian besar reponden termasuk dalam kategori rendah, yaitu dengan mengikuti kegiatan penyuluhan 1 sampai 4 kali dalam 1 tahun. Menurut keterangan petani, hal ini dikarenakan kurangnya kegiatan penyuluhan pertanian dari instansi-instansi terkait yang dilakukan di Desa Tonsewer. Kegiatan nonformal yang biasa diikuti petani itu merupakan kegiatan penyuluhan dan promosi produk dari perusahaan-perusahaan pestisida.

5) Umur

Umur petani akan mempengaruhi kemampuan fisik dan respon terhadap hal-hal baru dalam menjalankan usahataninya,distribusi pendidikan non formal responden disajikan dalam Tabel 13.

Tabel 13. Distribusi Responden Berdasarkan Umur

\begin{tabular}{|c|c|c|c|c|c|}
\hline Variabel & Kriteria & Skor & $\begin{array}{c}\text { Jumlah } \\
\text { responden }\end{array}$ & $\%$ & Median \\
\hline \multirow[t]{9}{*}{ Umur } & $25-39$ & 5 & 17 & 35,42 & \multirow{9}{*}{4} \\
\hline & Tahun & & & & \\
\hline & $40-50$ & 4 & 13 & 27,08 & \\
\hline & Tahun & & & & \\
\hline & $51-60$ & 3 & 9 & 18,75 & \\
\hline & Tahun & & & & \\
\hline & $61-70$ & 2 & 6 & 12,50 & \\
\hline & Tahun & & & & \\
\hline & >70Tahun & 1 & 3 & 6,25 & \\
\hline Jumlah & & & 48 & 100,00 & \\
\hline
\end{tabular}

Sumber : Analisis Data Primer 5

Umur akan berpengaruh terhadap pengambilan keputusan dan tindak-lanjut adopsi suatu inovasi seseorang. Tabel 13 menunjukkan bahwa umur sebagian besar responden tergolong usia produktif, sehingga memungkinkan petani memilih untuk menerapkan suatu inovasi.

6) Tingkat Kosmopolitan

Tingkat kosmopolitan responden yang pergi keluar daerah untuk mencari informasi inovasi terbaru keluar kota dalam kurun waktu setahun, distribusi tingkat kosmopolitan respondendalam Tabel 14. 


\begin{tabular}{|c|c|c|c|c|c|}
\hline Variabel & Kriteria & skor & $\begin{array}{c}\text { Jumlah } \\
\text { responden }\end{array}$ & $\%$ & Median \\
\hline \multirow{5}{*}{$\begin{array}{l}\text { Tingkat } \\
\text { Kekosmopol } \\
\text { itan }\end{array}$} & $\geq 6$ kali & 5 & 9 & 18,75 & \multirow{5}{*}{2} \\
\hline & 5 kali & 4 & 5 & 10,42 & \\
\hline & 4 kali & 3 & 3 & 6,25 & \\
\hline & 3 kali & 2 & 7 & 14,58 & \\
\hline & $\begin{array}{c}1-2 \\
\text { kali }\end{array}$ & 1 & 24 & 50,00 & \\
\hline Jumlah & & & 48 & 100,00 & \\
\hline
\end{tabular}

Tingkat kosmopolitan dapat dilihat dari frekuensi dan jarak kegiatan bepergian maupun pemanfaatan media massa. Dari Tabel 14 menunjukkan tingkat kosmopolitan sebagian besar responden tergolong rendah dengan median 2.

\section{Adopsi Responden Terhadap Budidaya Bawang merah (Allium ascalonicum)}

Tingkat adopsi responden terhadap budidayaBawang merah meliputi pengolahan tanah, penanaman, pemupukan, pengairan, pengendalian hama, penyakit dan gulma, dan panen dan pasca panen.

a. Pengolahan Tanah

Pengolahan Tanah bertujuan untuk mempersiapkan media tanam untuk pertanaman bawang merah meliputi sebagai berikut:

1. Pembersihan lahan,

2. Pembongkaran lapisan tanah,

3. Pelumpuran, dan

4. Pembuatan pematang lahan dengan bantuan cangkul.

Distribusi tahap pengolahan tanah disajikan dalam Tabel 15.

\begin{tabular}{|c|c|c|c|c|c|}
\hline Variabel & Kriteria & Skor & $\begin{array}{c}\text { Jumlah } \\
\text { responden }\end{array}$ & $\%$ & Median \\
\hline \multirow[t]{5}{*}{$\begin{array}{l}\text { Pengolahan } \\
\text { tanah }\end{array}$} & $\begin{array}{l}\text { - Melakukan 5- } \\
6 \text { tahapan } \\
\text { pengolahan } \\
\text { tanah }\end{array}$ & 5 & 48 & 100,00 & \\
\hline & $\begin{array}{l}\text { - Melakukan } 3 \text { - } \\
4 \text { tahapan } \\
\text { pengolahan } \\
\text { tanah }\end{array}$ & 4 & 0 & 0 & \\
\hline & $\begin{array}{l}\text { - Melakukan } 2 \\
\text { tahapan } \\
\text { pengolahan } \\
\text { tanah }\end{array}$ & 3 & 0 & 0 & 5 \\
\hline & $\begin{array}{l}\text { - Melakukan } 1 \\
\text { tahapan } \\
\text { pengolahan } \\
\text { tanah }\end{array}$ & 2 & 0 & 0 & \\
\hline & $\begin{array}{l}\text { - Tidak } \\
\text { melakukan } \\
\text { tahapan }\end{array}$ & 1 & 0 & 0 & \\
\hline Jumlah & & & 48 & 100,00 & \\
\hline
\end{tabular}

Pengolahan Tanah, yaitu persiapan lahan yang akan ditanami. Pengolahan dilakukan dengan bajak ataupun traktor, dari Tabel 15 menunjukkan keseluruhan responden melakukan pengolahan tanah dengan sangat baik, yaitu median 5. Menurut keterangan, hal ini karena para responden telah mengenal teknik pengolahan lahan secara turun temurun dari orang tua mereka, hanya saja terdapat perbedaan pada peralatan yang mereka gunakan. Oleh karena itu, dengan penggunaan traktor yang mempersingkat waktu pengolahan tanah dan menghemat tenaga kerja berdampak pada pertanian di Desa Tonsewer cenderung berkembang.

b. Penanaman

Penanaman bawang merah sebaiknya dilakukan setelah tujuh hari pemberian pupuk kandang, dengan jarak tanam $20 \mathrm{~cm} \times 10 \mathrm{~cm}$. Teknis penanaman yaitu dengan membenamkan $2 / 3$ bagian bibit (umbi) ke dalam tanah. Penyiraman tanah perlu dilakukan sebelum maupun sesudah tanam. Untuk mencegah bibit yang baru ditanam busuk, perlu ditaburkan Dithane M-45 atau abu dapur ke bedengan. Dithane M-45 juga dapat disemprotkan ke permukaan bedengan.

\begin{tabular}{|c|c|c|c|c|c|}
\hline Variabel & Kriteria & Skor & $\begin{array}{c}\text { Jumlah } \\
\text { Responden }\end{array}$ & $\%$ & Median \\
\hline \multirow[t]{5}{*}{ Penanaman } & $\begin{array}{l}\text { - Melakukan 5 } \\
\text { tahapan } \\
\text { penanaman }\end{array}$ & 5 & 48 & 100,00 & \\
\hline & $\begin{array}{l}\text { - Melakukan } 4 \\
\text { tahapan } \\
\text { penanaman }\end{array}$ & 4 & 0 & 0,00 & \\
\hline & $\begin{array}{l}\text { - Melakukan } 3 \\
\text { tahapan } \\
\text { penanaman }\end{array}$ & 3 & 0 & 0,00 & 5 \\
\hline & $\begin{array}{l}\text { - Melakukan } 2 \\
\text { tahapan } \\
\text { penanaman }\end{array}$ & 2 & 0 & 0,00 & \\
\hline & $\begin{array}{l}\text { Melakukan } \\
\text { hanya } 1 \\
\text { tahapan } \\
\text { penanaman }\end{array}$ & 1 & 0 & 0,00 & \\
\hline Jumlah & & & 48 & 100,00 & \\
\hline
\end{tabular}

Tabel 16 menunjukkan keseluruhan responden (100\%) melakukan 5 tahapan penanaman dengan sangat baik dengan median 5.Hal ini disebabkan oleh teknik penanaman baik dan yang sangat menghemat waktu dan tenaga kerja.

c. Pemupukan

Anjuran pemupukan secara umum untuk bawang merah adalah sebagai berikut : (a) pupuk dasar berupa pupuk kandang matang (siap digunakan) sebanyak $10 \mathrm{t} / \mathrm{ha}$, (b) pupuk Urea, SP-36 dan $\mathrm{KCl}$ masing-masing sebanyak $100 \mathrm{~kg}, 150-200 \mathrm{~kg}$, dan $200 \mathrm{~kg}$ per hektar, diberikan secara larikan pada saat tanam, (c) 
pemupukan susulan dilakukan pada saat tanaman berumur 35 hari yakni Urea sebanyak $100-150$ $\mathrm{kg} / \mathrm{ha}$, diberikan secara larikan.

\begin{tabular}{|c|c|c|c|c|c|}
\hline Variabel & Kriteria & Skor & $\begin{array}{c}\text { Jumlah } \\
\text { responden }\end{array}$ & $\%$ & Median \\
\hline \multirow[t]{5}{*}{$\begin{array}{l}\text { Pemeliharaan } \\
\text { (Pemupukan) }\end{array}$} & $\begin{array}{l}\text { - Pengaplikasian } \\
\text { semua jenis } \\
\text { pemupukan }\end{array}$ & 5 & 0 & 0,00 & \\
\hline & $\begin{array}{l}\text { Pengaplikasian } \\
\text { semua pupuk, } \\
\text { tanpa pupuk } \\
\text { kandang }\end{array}$ & 4 & 34 & 70,83 & \\
\hline & $\begin{array}{l}\text { - Pengaplikasian } \\
\text { semua pupuk } \\
\text { ANORGANIK } \\
\text { tanpa pupuk } \\
\text { kandang dan } \\
\text { pupuk cair }\end{array}$ & 3 & 14 & 29,17 & 4 \\
\hline & $\begin{array}{l}\text { - Hanya } \\
\text { pengaplikasian } \\
\text { UREA }\end{array}$ & 2 & 0 & 0,00 & \\
\hline & $\begin{array}{l}\text { - Tidak ada } \\
\text { pemupukan } \\
\text { sama sekali } \\
\end{array}$ & 1 & 0 & 0,00 & \\
\hline Jumlah & & & 48 & 100,00 & \\
\hline
\end{tabular}

Tabel 17 menunjukkan pengetahuan tentang pupuk dan pemupukan sudah sangat tinggi yaitu dengan median 4, dapat dilihat dari pengaplikasian jenis-jenis pupuk pada lahan usahatani. Menurut keterangan responden alasan tidak digunakannya pupuk kandang karena alasan efisiensi waktu, tenaga dan modal.

d. Pengairan

Bawang merah merupakan tanaman yang memerlukan cukup air tetapi tidak tahan genangan/kondisi becek. Penyiraman sebaiknya dilakukan menggunakan semprotan. Untuk tanaman berumur $0 \quad-10$ hari, penyiraman dilakukan 2 (dua) kali yakni pagi dan sore hari, sedangkan sesudah umur tersebut penyiraman cukup dilakukan sekali sehari (sebaiknya dilakukan pada pagi hari).

Tabel 18. Distribusi Responden Berdasarkan Pengairan

\begin{tabular}{|c|c|c|c|c|c|}
\hline Variabel & Kriteria & Skor & $\begin{array}{c}\text { Jumlah } \\
\text { responden }\end{array}$ & $\%$ & Median \\
\hline \multirow[t]{5}{*}{$\begin{array}{c}\text { Pemeliharaan } \\
\text { (Pengairan) }\end{array}$} & $\begin{array}{c}\text {-2-3 hari } \\
\text { sekali }\end{array}$ & 5 & 36 & 75,00 & \multirow{5}{*}{5} \\
\hline & $\begin{array}{c}\text { - 4-5 hari } \\
\text { sekali }\end{array}$ & 4 & 9 & 18,75 & \\
\hline & $\begin{array}{r}-6 \text { hari } \\
\text { sekali }\end{array}$ & 3 & 2 & 4,17 & \\
\hline & $\begin{array}{l}\text { - } 1 \text { minggu } \\
\text { sekali }\end{array}$ & 2 & 1 & 2,08 & \\
\hline & $\begin{array}{c}\bullet>1 \text { minggu } \\
\text { sekali }\end{array}$ & 1 & 0 & 0,00 & \\
\hline Jumlah & & & 48 & 100,00 & \\
\hline
\end{tabular}

Dari Tabel 18 dapat dilihat bahwa para responden sangat memperhatikan genangan air pada lahan usahatani, adalah sangat tinggi yaitu dengan median 5. Menurut keterangan responden pengontrolan air dipengaruhi oleh letak areal pertanaman bawang merah itu sendiri.

e. Pengendalian Hama Penyakit dan Gulma

Pengontrolan rutin terhadap gejala serangan hama dan penyakit, serta gulma yang muncul pada areal pertanaman bawang merah menjadi kunci danmengurangi resiko gagal panen. Pengendalian dilakukan apabila terdapat gejala serangan, dapat dilakukan secara fisik, biologis, kimia, maupun kultur tenis. Distribusi tahap pengendalian hama, penyakit dan gulma disajikan dalam Tabel 19.

\begin{tabular}{|c|c|c|c|c|c|}
\hline Variabel & Kriteria & Skor & $\begin{array}{c}\text { Jumlah } \\
\text { responden }\end{array}$ & $\%$ & Median \\
\hline \multirow{5}{*}{$\begin{array}{l}\text { Pengendalian } \\
\text { Hama, } \\
\text { Penyakit dan } \\
\text { Gulma }\end{array}$} & $\begin{array}{l}\text { - Melakukan } 4 \\
-5 \text { kegiatan } \\
\text { PHP tanaman }\end{array}$ & 5 & 37 & 77,08 & \multirow{6}{*}{5} \\
\hline & $\begin{array}{l}\text { - Melakukan } \\
\text { pengendalian } \\
\text { PHP tanpa } \\
\text { sanitasi areal } \\
\text { pertanaman }\end{array}$ & 4 & 11 & 22,92 & \\
\hline & $\begin{array}{l}\text { - Melakukan } \\
\text { hanya } 3 \\
\text { pengendalia } \\
\text { hama, } \\
\text { penyakit, dan } \\
\text { gulma }\end{array}$ & 3 & 0 & 0,00 & \\
\hline & $\begin{array}{l}\text { - Hanya } \\
\text { melakukan } 2 \\
\text { pengendalia } \\
\text { hama dan } \\
\text { penyakit }\end{array}$ & 2 & 0 & 0,00 & \\
\hline & $\begin{array}{l}\text { - Hanya } \\
\text { melakukan } 1 \\
\text { pengendalian } \\
\end{array}$ & 1 & 0 & 0,00 & \\
\hline Jumlah & 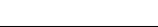 & & 48 & 100,00 & \\
\hline
\end{tabular}

Dari Tabel 19 dapat dilihat bahwa tindakan responden terhadap pengendalian hama, penyakit serta gulma sangat tinggi, yaitu dengan median 5 . Sejak metode penanaman Tabela mulai diaplikasikan di Desa Tonsewer, pengendalian hama, penyakit serta gulma lebih mengarah kepada pengendalian secara kimia, yaitu dengan penggunaan berbagai jenis pestisida, namun dari keterangan beberapa responden masih ada beberapa yang dilakukan secara teknis.

f. Panen dan Pascapanen

Panen dilakukan apabila tanaman telah berumur 65-75 hari setelah tanam. Tanaman yang telah siap dipanen memiliki ciri-ciri :

a) Tanaman telah cukup tua, dengan hampir 60$90 \%$ batang telah lemas dan daun menguning

b) Umbi lapis terlihat padat berisi dan sebagian tersembul di permukaan tanah 
c) Warna kulit umbi mengkilat atau memerah

d) Panen dilakukan dengan cara mencabut tanaman bersama daunnya dan diusahakan agar tanah yang menempel pada umbi dibersihkan.

e) Umbi yang telah dijemur dengan posisi daun berada di atas. Setelah daun kering, ikatan diperbesar dengan menyatukan 3-4 ikatan kecil menggunakan tali bambu. Selanjutnya ikatan dijemur kembali dengan posisi umbi di atas (selama 2-3 hari)

Bila umbi telah kering, umbi siap disimpan di gudang disajikan dalam Tabel 20.

\begin{tabular}{|c|c|c|c|c|c|}
\hline Variabel & Kriteria & Skor & $\begin{array}{c}\text { Jumlah } \\
\text { responden }\end{array}$ & $\%$ & Median \\
\hline \multirow[t]{5}{*}{$\begin{array}{l}\text { Panen dan } \\
\text { Pascapanen }\end{array}$} & $\begin{array}{l}\text { - Melakukan } \\
\text { semua } \\
\text { kegiatan } \\
\text { panen dan } \\
\text { pasca panen }\end{array}$ & 5 & 48 & 100,00 & \multirow{5}{*}{5} \\
\hline & $\begin{array}{l}\text { Melakukan } \\
\text { semua } \\
\text { kegiatan } \\
\text { panen dan } \\
\text { pasca panen }\end{array}$ & 4 & 0 & 0,00 & \\
\hline & $\begin{array}{l}\text { Melakukan } \\
\text { semua } \\
\text { kegiatan } \\
\text { panen dan }\end{array}$ & 3 & 0 & 0,00 & \\
\hline & $\begin{array}{l}\text { pasca panen, } \\
\text { tanpa } \\
\text { melakukan } \\
\text { penjemuran }\end{array}$ & 2 & 0 & 0,00 & \\
\hline & $\begin{array}{l}\text { melakukan } \\
\text { kegiatan } \\
\text { panen dan } \\
\text { pascapanen }\end{array}$ & 1 & 0 & 0,00 & \\
\hline Jumlah & & & 48 & 100,00 & \\
\hline
\end{tabular}

Dari Tabel 20 dapat dilihat bahwa kegiatan panen dan pascapanen bawang merah yang dilakukan petani di Desa Tonsewer sudah sangat baik dan tinggi.

\section{KESIMPULAN DAN SARAN}

\section{Kesimpulan}

Tingkat adopsi teknologi di desa Tonsewer sudah sangat tinngi, dan sudah menerapkan adopsi. Luas lahan semakin tinggi, pendapatan semakin banyak, Semakin bertambah umur seseorang semakin sulit seseorang tersebut menerima pengetahuan. Nilai diatas menunjukkan luas lahan, pendapatan, dan tingkat kosmopolitan memiliki hubungan sangat nyata terhadap tingkat adopsi teknologi budidaya bawang merah,pendidikan formal menunjukkan hubungan nyata terhadap tingkat adopsi teknologi budidaya bawang merah, sedangkanpendidikan non formal dan umur menunjukkan hubungan yang tidak nyata terhadap tingkat adopsi teknologi budidaya bawang merah. Nilai korelasi Spearman luas lahan, pendapatan, pendidikan formal, pendidikan non formal dan tingkat kosmopolitan menunjukkan arah korelasi positif, sedangkan umur menunjukkan arah korelasi negatif terhadap tingkat adopsi teknologi bawang merah.

\section{Saran}

Pemerintah hendaknya lebih aktif memberikan penyuluhan-penyuluhan ke desadesa secara rutin dan berkelanjutan dengan begitu para petani di kecamatan Tompaso pada khususnya di Desa Tonsewer mendapat pelatihan budidaya yang baik dan benar sesuai anjuran, hal ini dimaksudkan agar kegiatan penyuluhan bisa dilakukan secara terus menerus dengan begitu para petani bawang merah di Desa Tonsewer maupun petani di Kecamatan Tompaso pada khususnya mendapatkan pelatihan budidaya yang baik.

\section{DAFTAR PUSTAKA}

Anonim, 2000. Budidaya pertanian "Bawang merah (Allium ascalonicum)"

Dahlan M,S. 2010. Statistik Untuk Kedokteran dan Kesehatan (Deskriptif, Bivariat, dan Multivariat Dilengkapi Aplikasi Dengan SPSS).Salemba Medika. Jakarta.

Departemen Pertanian. 2008. Pedoman Umum Pengelolaan Anggaran Pembangunan Pertanian. Jakarta

Dinas Pertanian Tanaman Pangan dan Hortikultura. 2004. Pemberdayaan Penyuluhan Pertanian. Sumbar.

Dinas Pertanian Tanaman Pangan dan Hortikultura.2007. Pedoman Standar Minimal BPP Model di Sumatera Barat. Sumatera Barat.

Ibrahim J,T, Sudiyono A, Harpowo, 2003. Komunikasi dan Penyuluhan Pertanian, Bayumedia Publishing. Malang. 
IFOAM. 1997. Principles of Organic Agriculture. IFOAM General assembly in Adelaidin 1997.http://www.ifoam.com.

Levis, L,R, 1996. Komunikasi Penyuluhan Pedesaan. Citra Aditya Bakti. Bandung.

Maksum M, 1990. Sejarah Desa Kembang Mertha Kecamatan Dumoga. Kembang Mertha.

2010.Model-Model Pemberdayaan Masyarakat.UNS Press. Surakarta.

Panelewen J,H, 2010. Kebijakan dan program Peningkatan Produktivitas Padi Untuk Mewujudkan Swasembada Beras dan Swasembada Pangan Berkelanjutan di Provinsi Sulawesi Utara. Jurnal Pertanian. Manado. Dinas Pertanian dan Peternakan Sulawesi Utara.

Pracaya. 2004. Bertanam Sayuran Organik di Kebun, Pot dan Polibag. Cetakan ke-4. Penerbit Penebar Swadaya. Jakarta.

Prasetyo Y.T. 2002. Budidaya Padi Sawah TOT (Tanpa Olah Tanah).Kanisus, Yogyakarta.

Runtulalo, J, 2011. Profil Kecamatan seKabupaten Bolaang Mongondow, Kotamobagu. Badan Pusat Statistik Kabupaten Bolaang Mongondow.

Setiana, L. 2005. Teknik Penyuluhan dan Pemberdayaan Masyarakat.Ghalia Indonesia. Bogor.

Slamet, M. 2000. Dasar - dasar Penyuluhan dan Modernisasi Pertanian. Penerbit Bina Cipta. Bandung.

Soetrisno.Loekman 2002. Paradigma Baru Pertanian: Sebuah Tinjauan Sosiologis. Kanisius: Yogyakarta.

Soehartono, I, 2004.Metode Penelitian Sosial. PT. Remaja Rosdakarya, Bandung.

Sutanto.2002. Penerapan Pertanian Organik (Menuju Alternatif dan Berkelanjutan).

Kanisius. Jakarta.
Sukino, 2013.Membangun Pertanian Dengan Pemberdayaan Masyarakat Tani (Terobosan Menanggulangi Kemiskinan). Pustaka Baru Press. Yogyakarta.

Syahyuti, 2006. 30 Konsep Penting Dalam Pembangunan Pedesaan dan pertanian. Penjelasan tentang konsep, istilah, teori dan indikator serta variabel. Bina Rena Pariwara, Jakarta.

Syamsudin S, 2000.Dasar - dasar Penyuluhan dan Modernisasi Pertanian. Penerbit Bumi Aksara. Jakarta.

Runtulalo J, 2011. Profil Kecamatan seKabupaten Bolaang Mongondow, Kotamobagu. Badan Pusat Statistik Kabupaten Bolaang Mongondow.

Wisnuwardhani. 2002. Kajian Pengembangan Bisnis Pengusahaan Pergiliran Tanaman Hortikultura (Nasubi, Buncis, Kubis, Wortel) Menggunakan Sistem Pertanian Organik. Program Diploma III, Program Studi Manajemen Agribisnis Jurusan Ilmu-Ilmu Sosial Ekonomi Perrtanian. Fakultas Pertanian IPB: Bogor. 